\title{
UM PERCURSO GADAMERIANO NA PRODUÇÃO DE CONHECIMENTO EM ABORDAGEM CENTRADA NA PESSOA
}

\author{
A gadamerian route in the production of knowledge in a Person-Centered Approach
}

Una ruta gadameriana en la producción de conocimientos en un Enfoque Centrado en la Persona

EDSON DO NASCIMENTO BEZERRA

ALMir FERREIRA DA SiLva JUNIOR

\begin{abstract}
Resumo: O presente artigo objetiva apresentar o percurso teórico-metodológico, construído pelo primeiro autor em sua Dissertação de Mestrado sob a orientação do segundo, baseado na filosofia hermenêutica de Hans-Georg Gadamer. Justifica-se sua relevância por ser uma alternativa estruturada para a realização de pesquisas bibliográficas dentro do escopo da Abordagem Centrada na Pessoa (ACP). Para isso, procura-se inicialmente justificar a escolha da hermenêutica gadameriana em sua relação com o objetivo da pesquisa. Em seguida, apresenta-se a rede conceitual formada pela articulação das concepções preconceito, linguagem, tradição, atualização e fusão de horizontes que sustentam essa perspectiva, de forma que permita, posteriormente, sistematizar as fases investigação das informações, análise compreensiva e síntese hermenêutica para o desenvolvimento da pesquisa sobre o problema proposto. Finaliza-se o artigo com a constatação da potencialidade e proficuidade referente à aproximação, e consequente articulação, entre a ACP e a perspectiva filosófica gadameriana, com reflexões sobre as implicações quanto ao uso de um método hermenêuticofilosófico na produção de conhecimento na abordagem.
\end{abstract}

Palavras-chave: Abordagem Centrada na Pessoa; Hermenêutica Filosófica; Carl Rogers; Hans-Georg Gadamer.

Abstract: This article aims to present the theoretical-methodological route, built by the first author in his Master's Dissertation under the guidance of the second, based on Hans-Georg Gadamer hermeneutic-philosophical philosophy. Its relevance is justified because it is a structured alternative for conducting bibliographic research within the scope of the Person Centered Approach (PCA). For this, we initially want to justify an epistemological choice of gadamerian hermeneutics in its relation to the research objective. Then, we present the conceptual network formed by the articulation of prejudice, language, tradition, update and fusion of horizons that supports this perspective, in a ways that allows, later, to systematize the phases of information investigation, comprehensive analysis and hermeneutic synthesis to the development of research on the proposed problem. The article ends with the observation of the potentiality and proficiency related to the approximation, and consequent articulation, between PCA and the Gadamerian philosophical perspective, with reflections on the implications regarding the use of a hermeneutic-philosophical method in the production of knowledge in the approach.

Keywords: Person-Centered Approach; Philosophical Hermeneutic; Carl Rogers; Hans-Georg Gadamer.

Resumen: El presente artículo tiene como objetivo presentar el camino teórico-metodológico, construido por el primer autor en su disertación de maestría bajo la guía del segundo, basado en la filosofía hermenéutica de Hans-Georg Gadamer. Su relevancia se justifica porque es una alternativa estructurada para realizar investigaciones bibliográficas dentro del alcance del Enfoque Centrado en la Persona (ECP). Para eso, se busca inicialmente justificar la elección de la hermenéutica gadameriana en su relación con el objetivo de la investigación. En seguida, presenta-se la red conceptual formada por la articulación de las concepciones prejuicio, lenguaje, tradición, atualización, y fusión de horizontes que sostiene esa perspectiva de forma que permita, posteriormente, sistematizar las fases investigación de las informaciones, analisis comprensiva y síntesis hermenéutica para el desarrollo de la investigación sobre el problema propuesto.El artículo finaliza con la verificación de la potencialidad y rentabilidad relacionadas con la aproximación, y la articulación consiguiente, entre ECP y la perspectiva filosófica gadameriana, con reflexiones sobre las implicaciones con respecto al uso de un método hermenéutico-filosófico en la producción de conocimiento en el enfoque.

Palabras-clave: Enfoque Centrado en la Persona; Hermenéutica Filosófica; Carl Rogers; Hans-Georg Gadamer.

\section{Introdução}

A produção de conhecimento no contexto científico-acadêmico demanda que o caminho a ser trilhado, nesse sentido, seja seguro o suficiente de modo que o saber derivado desse processo ofereça um grau de clareza e validade exigidos minimamente pela sua comunidade referente. Para discutir, dentro desses critérios estabelecidos, a noção de abordagem centrada na pessoa ${ }^{1}$, tal qual formulada por Carl Ransom Rogers e John Keith Wood (2013), objeto de pesquisa da Dissertação de Mestrado do primeiro autor (Bezerra, 2018), foi construída, em parceria com o segundo autor (orientador da Dissertação), uma proposta de percurso teórico-metodológico baseado na filosofia hermenêutico-filosófica de Hans-Georg Gadamer (1900-2002). 
Ainda que adequada, há pouca articulação entre Abordagem Centrada na Pessoa e a Hermenêutica Filosófica, percepção que foi sendo fundamentada no decorrer do levantamento bibliográfico da produção acadêmica nacional e internacional sobre o tema, onde se buscou estudos que apresentassem, em seu resumo e/ou palavras-chave os descritores Hermenêutica Filosófica, Gadamer, Abordagem Centrada na Pessoa, Psicologia Humanista e Carl Rogers. Os estudos - nos idiomas português, inglês ou espanhol - teriam que ter uma combinação que indicasse, conforme análise posterior do corpo do texto, a referida aproximação entre a Abordagem Centrada na Pessoa e a Hermenêutica Filosófica. O levantamento foi realizado no catálogo de teses e dissertações do Portal de Periódicos da Coordenação de Aperfeiçoamento de Pessoal de Nível Superior (CAPES), e nos Portais da Rede Scientific Electronic Library Online (SciELO) e dos Periódicos Eletrônicos de Psicologia (PePSIC).

Verificaram-se internacionalmente os seguintes registros relacionados a essa aproximação entre Rogers e Gadamer: o artigo de Martin e Dawda (1999), que utilizou uma análise hermenêutica baseada no neo-gadameriano Hans Kögler para realização de estudo sobre empatia em psicoterapia; o artigo de Rennie (2007), em que faz referência a uma vinculação entre o método hermenêutico e a Psicologia Humanista, seja pelo uso implícito dessa metodologia no desenvolvimento das teorias de Maslow e Rogers, seja na sua utilização em pesquisas qualitativas; e o artigo de Worsley (2016), que trata da utilização da hermenêutica de Paul Ricoeur como recurso de análise dos significados e narrativas de vida desenvolvidos pelo cliente em um processo terapêutico. Em âmbito nacional, verificaram-se os seguintes registros: o artigos de Vieira e Freire (2006) e Miranda e Freire (2012), assim como a tese de Vieira (2017), que utilizam metodologicamente a noção de fusão de horizontes gadameriana para sustentar as discussões realizadas (respectivamente sobre a questão da alteridade radical no pensamento de Rogers, o processo de comunicação entre psicoterapeuta e cliente nas fases do pensamento rogeriano, e as formas que a alteridade, na perspectiva levinasiana, vai tomando no decorrer das diferentes fases da teoria psicoterápica rogeriana); outra referência encontrada foi a tese de Melo (2012), em que a autora estrutura uma proposta em clínica do trabalho cuja metodologia articula a fenomenologia merleau-pontyana com a hermenêutica filosófica gadameriana. Dessa forma, observa-se por meio desse levantamento a escassez bibliográfica quanto à articulação entre as perspectivas teóricas em questão.

Como recorte feito a partir da Dissertação do primeiro autor (Bezerra, 2018), cuja construção conceitual transita entre os legados de Rogers e de Gadamer, esse artigo tem por objetivo apresentar o percurso teórico-metodológico desenvolvido e baseado na hermenêutica filosófica gadameriana. Sua relevância justifica-se por ser uma alternativa estruturada para a realização de pesquisas bibliográficas em Abordagem Centrada na Pessoa (ACP). Para isso, procura-se inicialmente justificar a escolha da hermenêutica gadameria na em sua relação com a noção de abordagem centrada na pessoa, uma vez que se entende que o método deve derivar e se adequar ao seu objeto (no caso, a compreensão hermenêutico-gadameriana da noção citada), ao funcionar como uma estratégia de aproximação e apropriação exploratória que considere suas especificidades. Em seguida, apresenta-se a rede conceitual que sustenta essa perspectiva filosófica, de forma que permita, posteriormente, sistematizar as fases do percurso metodológico elaborado para o desenvolvimento da pesquisa sobre o problema proposto. Finaliza-se o artigo com algumas reflexões e desafios provenientes do processo de constituição deste texto, como a concepção de que diante da primazia do objeto de estudo, o método funciona como uma estratégia de aproximação e apropriação exploratória desse, possibilitando um processo que ocorre de modo dialético e contínuo, sem a pretensão de determinação e dominação, mas de diálogo e troca.

\section{A Noção de Abordagem Centrada na Pessoa como Objeto de Pesquisa}

O legado teórico e prático do psicólogo norteamericano Carl Ransom Rogers (1902-1987) associase, atualmente, à ACP. Mas a sua proposta em Psicologia nem sempre esteve identificada assim. Recebeu outras denominações (aconselhamento não-diretivo, terapia centrada no cliente, abordagem centrada no cliente), e apenas, em 1975, assumiu essa designação para identificar um workshopproposta de trabalho intensivo com grandes grupos, desenvolvida por Rogers -, realizado em Ashland (Estados Unidos da América - EUA), conforme John Keith Wood (1934-2004) descreve: "Pela primeira vez, um workshop seria chamado de 'abordagem centrada na pessoa', com o propósito de refletir um campo cada vez maior de aplicações” (Wood, 2013, p. 49, grifos do autor).

Essa ampliação no campo de aplicações do trabalho de Rogers provém desde o início da década de 1960, quando ele deixa a carreira acadêmica, e abandona o seu principal foco de pesquisa e produção teórica, a psicoterapia individual. Rogers passa a propor a aplicação da sua teoria, a princípio voltada especificamente à relação psicoterápica, em outras áreas, por exemplo trabalhos com grupos (grupo de encontro), educação (o ensino centrado no aluno) e relações familiares. $\mathrm{O}$ autor também propõe a inclusão, em sua teoria, de elementos dos paradigmas holístico, sistêmico e fenomenológico, ainda que não tenha ancorado esses elementos em 
estratégias de intervenção (Branco, 2010, 2015). De acordo com Wood (2013) - membro do staff de profissionais que trabalhava com Rogers na facilitação dos workshops -, não cabia mais falar em abordagem centrada no cliente, uma denominação híbrida que, se por um lado já não mais se identificava com a terapia (centrada no cliente), por outro trazia um forte traço da prática clínica no termo cliente:

Desde Ashland, eu me encontrava bastante ocupado. Havíamos mudado o nome do nosso workshop de Abordagem Centrada no 'Cliente' para Abordagem Centrada na 'Pessoa' porque 'cliente' era um conceito muito restrito para a realidade dos workshops que se desenvolvia. Ninguém era cliente de ninguém. Juntos, éramos pessoas. Mas seria o termo 'abordagem centrada na pessoa' suficientemente preciso? Seria a postura assumida por nós realmente centrada na pessoa? Definitivamente, não era uma postura centrada na 'persona'. E agora, diferentemente da terapia centrada no cliente, não estava exclusivamente centrada no pessoal. Era centrada em uma subjetividade que atravessava os interrelacionamentos entre pessoas e entre certas realidades transpessoais. Poderia ser chamada de 'centrada na vida'. (Wood, 2013, pp. 63-64).

É possível problematizar que a mudança da nomenclatura que passou a ser adotada parece ultrapassar o sentido único da ampliação das áreas de aplicação do trabalho de Rogers. Havia uma disposição por valorizar a potencialização das pessoas em relações menos vinculadas aos modelos tradicionais e já estabelecidos, como o psicoterápico, por exemplo. Logo, existia uma abertura às possibilidades relacionais com um perfil menos individualista e mais relacional, cuja dimensão incluía aspectos pouco ortodoxos, como as experiências de natureza transpessoal - estados alterados e ampliados de consciência, considerada em uma concepção espiritual e mística (Boainain Junior, 1998). Não se tratava, pois, de pensar o ser humano em seu caráter particular (persona), mas privilegiar o comportamento humano no horizonte interpessoal ou mesmo transpessoal, daí contemplar uma pluralidade de campos que expressam relações intersubjetivas e a amplitude da vida.

A ênfase dada ao potencial da pessoa como fator de transformação é explorada por Rogers (1977/1978) em Sobre o Poder Pessoal (Carl Rogers On Personal Power, 1977), em que formaliza a identidade da sua proposta como uma abordagem centrada na pessoa. No entanto, a referida nomenclatura, ainda que tenha se adequado melhor ao que Rogers entendeu como um progresso na extensão a uma ampla variedade de campos longe do seu ponto de origem (a psicoterapia), desperta nele vivo interesse em considerar o impacto e a influência que sua proposta pode provocar no relacionamento entre pessoas. Em outras palavras, entre uma pessoa e um grupo, ou entre grupos, ao ponto de Rogers (1977/1978) definir a abordagem centrada na pessoa, na introdução da obra, como uma abordagem que não dá poder à pessoa pelo simples fato de nunca se propor a retirálo dela.

Considerando essa forte impressão de sua origem, é possível se voltar para a essência da definição de forma mais detalhada (e um tanto quanto paradoxal) apresentada por Wood et al. (1994/2008). Essa iniciativa tem a finalidade de romper com a mera transposição dos conceitos principais da teoria da terapia centrada no cliente para a abordagem centrada na pessoa, como se fosse apenas uma extensão da relação psicoterápica elaborada por Rogers para outros campos distintos das relações humanas. Segundo os autores,

A Abordagem Centrada na Pessoa não é uma teoria, uma terapia, uma psicologia, uma tradição. Não é uma linha, como por exemplo, a linha Behaviorista. Embora muitos tenham notado um posicionamento existencial em suas atitudes, e outros tenham se referido a uma perspectiva fenomenológica em suas intenções, não é uma filosofia. Acima de tudo, não é um movimento, como por exemplo o movimento trabalhista. É meramente uma abordagem; nada mais, nada menos. É um 'jeito de ser' ... ao se deparar com certas situações. (Wood et al., 1994/2008, p. 14, grifo do autor).

A ACP, conforme este trecho, necessita ser definida no horizonte daquilo que a nega. Ou seja, mais do que afirmar o que ela é, o esforço maior do autor é sustentar que sua identidade se fortalece no registro de suas diferenças. Nesse sentido, verificase um empenho de diferenciação que contempla as configurações anteriores do trabalho de Rogers, principalmente com a terapia centrada no cliente, o que se mostra relevante para compreender a densidade dessa transposição de conceito e de prática. Nesse sentido, a compreensão é efetivada aqui em uma perspectiva dialética que busca a consolidação da identidade pelo registro de suas diferenças.

Wood se esforça em diferenciar a ACP das escolas e linhas tradicionais da Psicologia. Não entende a ACP como um modelo a ser utilizado e replicado em condições de atendimento psicoterápico ou grupal. Evita, assim, o empobrecimento da proposta de Rogers, impedindo restringi-la a algo próximo a um tecnicismo científico-terapêutico sustentado epistemologicamente. Da mesma forma, procura distanciar a ACP de um movimento a ser abraçado e seguido por adeptos, como um modo de verdade estabelecida, inquestionável e passível de transmissão geracional. Por outro lado, percebe-se 
que o autor está preocupado em ressaltar o aspecto mais característico e potencialmente significativo da ACP: seu caráter aberto, inacabado, projetado e incompleto de atuação, fundamentalmente estabelecido na pessoalidade, porém sem cair no limite individualista da pessoa, sem se propor a servir como modelo, referência ou sustentação para qualquer coisa. Desse modo, Wood et al. (1994/2008) definem a ACP como uma abordagem, um jeito de ser.

Mas afinal, é possível conhecer a ACP fora dos parâmetros estabelecidos pela cientificidade e filosofia, vetados por Wood nessa breve definição? De que modo uma abordagem pode ser legitimada, independente dos padrões convencionais de saber em Psicologia? Como possibilitar uma compreensão da $A C P$ que respeite estritamente os vetos apresentados por Wood? Por conseguinte, há nessa proposta de apreensão cognitiva que legitime tais limites uma fundamentação teórico-conceitual que, por sua vez, instaura uma práxis diferenciada nessa transição de cliente à pessoa, se é que essa transição traz alguma novidade conceitual. É nesse sentido que a atitude hermenêutica gadameriana permite desconfiar do que está dado e propagado pelo escopo woodiano e rogeriano, por meio do desvelamento de um novo horizonte enquanto possibilidade de resposta a tais indagações.

Ao considerar, principalmente, estes vetos woodianos, uma vez que John Keith Wood foi um colaborador ativo de Rogers e diretamente presente no processo de configuração do termo abordagem centrada na pessoa (Wood, 2013), conhecer a ACP implica tomar como ponto de partida o esclarecimento daquilo que ela não é, buscando assim sua identidade específica, a partir de sua ressignificação, distinta da terapia centrada no cliente anterior a ela.

Assim, sob tal referência, optou-se pela via da hermenêutica filosófica desenvolvida por Hans-Georg Gadamer (1900-2002) como base de aproximação e apropriação do tema, de modo teórico e metodológico para pensar e buscar compreender a questão proposta. Tal escolha se justifica pela crítica hermenêutico-filosófica dirigida ao paradigma metodológico científico moderno, em função da qual a compreensão é tomada em seu modo de ser e privilegiada em um diálogo vivo com a tradição; daí despontar a hermenêutica como uma espécie de racionalidade que se propõe a compreender e investigar experiências e questões na perspectiva de suas atualizações históricas. Nesse sentido, importante considerar que a proposta de Gadamer busca resgatar a validade de saberes, como o artístico, histórico e todo aquele que se insere enquanto experiência de linguagem, estabelecidos de modo independente de um modelo sustentado metodologicamente nos cânones científicos convencionais (Lawn, 2011).
A escolha da perspectiva hermenêutica filosófica gadameriana também se justifica pela necessária consideração da compreensão em seu contexto histórico-cultural, uma vez que a formação desse saber é sempre constituída por uma relação de abertura permanente junto à contingência das coisas e ao diálogo vivo com a tradição e com a modernidade dos fatos e acontecimentos, tornando-o absolutamente falível, aberto e coloquial, coloquial aqui entendido como derivado de um colóquio, um diálogo entre ideias e contexto (Lawn, 2011).

Nessa perspectiva, compreende-se que uma reflexão sobre a abordagem centrada na pessoa não pode fugir de uma contextualidade absolutamente distinta da que envolveu a constituição da terapia centrada no cliente, ainda que a abordagem derive, em grande medida, do modelo psicoterápico rogeriano. No entanto, conforme abordado anteriormente, a abordagem não é apenas uma ampliação das áreas de aplicação da terapia centrada no cliente, inclusive pela mudança histórico-cultural que envolveu Carl Rogers na reelaboração de suas ideias.

Em uma visada epistemológica e historiográfica, sem desconsiderar a importância das influências externalistas no processo de mudança investigado, ou seja, quanto à dinâmica das influências externas (fatores sociopsicológicos e, mais amplamente, aos movimentos da sociedade e da cultura) sobre o pensamento de Rogers, essa pesquisa hermenêutica possui caráter internalista, em que a compreensão do arranjo teórico sustenta-se na própria evolução do pensamento rogeriano (Massimi, Campos \& Brozek, 2008).

Assim, é importante considerar que o estabelecimento de um método influenciado pela hermenêutica filosófica de Gadamer pressupõe a sua implicação ao problema ético da concreção de uma teoria. Dito de outra forma, todo conhecimento, hermeneuticamente pensando, requer um sentido de aplicação nas situações concretas da vida. Nesse sentido, "o problema do método está inteiramente determinado por seu objeto" (Gadamer, 1960/2015, p. 413), uma vez que o conhecimento elaborado sobre esse objeto requer uma vinculação ao próprio momento do acontecer. Do ponto de vista hermenêutico, conhecer implica sempre um horizonte de aplicação.

Ao conceber a primazia do objeto de estudo, o método funciona como uma estratégia de aproximação e apropriação exploratória desse objeto, possibilitando que esse processo ocorra de modo dialético e contínuo, sem a pretensão de determinação e dominação, mas de diálogo e troca. Essa tarefa de interlocução autoriza que o objeto "fale", ou seja, proponha possibilidades interpretativas legítimas e possíveis sobre si, cujo caráter de aplicabilidade serve como referência para sua adequação.

Desse modo, o saber pretendido configura- 
se como um saber ético da phronesis, conforme a concepção aristotélica, diferente do saber teórico da episteme, uma vez que se volta para orientar a prática, a ação em seu caráter de aplicação (Gadamer, 1960/2015). Nesse sentido, não é explicativo, puro e objetivo, mas sim compreensivo, implicado e contextualizado. Enquanto método, não convém ser condutor de um processo investigativo, mas conduzido pela própria natureza do objeto estudado. Ao analisar a ciência moderna e sua dependência de um modelo metodológico, Gadamer (1963/1998, p. 13) identifica a proposta aristotélica da phronesis, enquanto saber ético voltado para a prática de vida, como

[...] o único modelo metodológico concebível da compreensão que as ciências humanas possuem delas mesmas, se se quer liberá-las da espúria restrição de perspectiva imposta pelo modelo das ciências da natureza. Ele confere uma justificativa científica à razão prática que sustenta toda a sociedade humana e que é ligada, há milênios, à tradição da retórica. Aqui o problema hermenêutico torna-se central; somente a concretização do geral lhe proporciona o seu conteúdo próprio.

Para tomar a hermenêutica filosófica como um método das ciências humanas, é necessário sustentá-la sobre uma base pré-estabelecida, anterior ao próprio saber a ser constituído entre o intérprete (sujeito) e o texto a ser interpretado (objeto de estudo), em uma relação circular - círculo hermenêutico - em que o significado de um todo se compreende por suas partes e, por conseguinte, são esclarecidas à luz do todo. Essa base é a compreensão hermenêutica que, construída a partir das pré-compreensões, é "prefigurada por uma tradição determinada em que vive o intérprete e que modela os seus preconceitos" (Gadamer, 1963/1998, p. 13, grifo nosso). Essa compreensão, que embasa o entendimento e a elaboração de um procedimento metodológico para a pesquisa sobre o objeto de estudo aqui apresentado, suscita a necessidade de uma apropriação da rede conceitual formada pelas concepções preconceito, linguagem, tradição, atualização e fusão de horizontes, que serão descritas e articuladas a seguir.

\section{Desenvolvimento da Metodologia Baseada na Rede Conceitual Hermenêutico-Filosófica}

De modo geral, preconceito representa todo e qualquer juízo que se forma antes do exame definitivo a ser formado sobre o objeto de estudo. Não configura um falso juízo em si, uma vez que pode ser correto ou não. "É só a fundamentação, a garantia do método (e não o encontro com a coisa como tal), que confere ao juízo sua dignidade"
(Gadamer, 1960/2015, p. 361). O resgate da noção de preconceito valida o juízo não fundamentado como legítimo e não definitivo do intérprete. Logo, ressalta a importância do método descrito acima, como estabelecedor de um possível caráter positivo ao preconceito como ponto de partida do exercício da compreensão hermenêutica.

A forma de realização da compreensão se dá através da mediação da linguagem, e, uma vez que tudo que pode ser compreendido reveste-se desse caráter universal, nesse caso, é possível incluir o indizível, já que a infinitude da conversação, enquanto acontecimento concreto da linguagem, sempre alcança a pré-figuração espontânea da compreensão hermenêutica (Gadamer, 1960/2015). Para tornar mais completo o sentido constitutivo da linguagem, também é preciso considerar a noção de tradição enquanto comunidade de preconceitos fundamentais e sustentadores, cuja validade não precisa de fundamentação, pois nos determina espontaneamente pelo sentido de pertença a um contexto histórico-efeitual e sobre a qual nossos costumes são criados e fundados. Essa concepção de história efeitual deriva da noção gadameriana Wirkungsgeschichte, comumente traduzida também como "história dos efeitos", "história efetiva", "princípio de produtividade histórica" ou "história das influências e recepções”. O termo nos remete a um sentido de uma história dos efeitos, das consequências, dos resultados (do alemão Wirkung). É a tradição enquanto contexto estrutural comum de pré-compreensão que nos conforma humanamente falando, em que desde sempre já nos encontramos. Em nossa língua, tradição corresponde aos termos Traditio (do latim, cujo significado é "transmissão", "entrega") e Überlieferung (de Überliefern, como "transmitir" e liefern, que significa "prover", "entregar"). Assim, tradição refere-se à fonte legítima de preconceitos cuja influência sempre afeta o lugarcomum em que vivemos (Gadamer, 1960/2015). A inevitável autoridade dessas vozes que ressoam sobre o nosso horizonte conceitual diferencia-se, na perspectiva aqui adotada, do registro proveniente da ingenuidade objetivista da História como legado do passado.

Mais do que configurar um procedimento hermenêutico, essa proposta metodológica priorizou "esclarecer as condições sob as quais surge compreensão” (Gadamer, 1960/2015, p. 391), uma vez que para o filósofo, tais condições precisam estar dadas antes de se configurar qualquer modo de aplicação procedimental, pois se referem ao fato de que

[...] os preconceitos e opiniões prévias que ocupam a consciência do intérprete não se encontram à sua livre disposição. O intérprete não está em condições de distinguir por si mesmo e de antemão os preconceitos produtivos, que 
tornam possível a compreensão, daqueles outros que a obstaculizam e que levam a malentendidos. (Gadamer, 1960/2015, p. 391).

Assim, para que essa distinção seja feita, é necessário refletir sobre o modo como isso ocorre na pesquisa, ou seja, através da diferença histórica e contextual existente entre o intérprete (o autor da Dissertação base para este artigo) e os autores estudados (Rogers e Wood). Ao se referir ao texto como expressão de uma pretensão de verdade passível de ser compreendida, o filósofo destaca que

Cada época deve compreender a seu modo um texto transmitido, pois o texto forma parte do todo da tradição na qual cada época tem um interesse objetivo e onde também ela procura compreender a si mesma. Como se apresenta a seu intérprete, o verdadeiro sentido de um texto não depende do aspecto puramente ocasional representado pelo autor e seu público originário. Ou pelo menos não se esgota nisso, pois sempre é determinado também pela situação histórica do intérprete e consequentemente por todo curso objetivo da história. (Gadamer, 1960/2015, p. 392).

Ainda que imediata, a compreensão subordinase à autoridade anônima da tradição que sempre determina nosso ser histórico e finito. Sua legitimidade sobre nossa ação não requer qualquer tipo de fundamentação, uma vez que sua autoridade tem poder espontâneo sobre os costumes criados. A tradição não é um corpo de ideias que se mantém estável e sem rupturas no decorrer do tempo. Trata-se, isto sim, daquilo que adquire um caráter de continuidade e conservação e, inevitavelmente, está sempre atuante crítica e dinamicamente nas mudanças históricas e em seu processo de atualização (Gadamer, 1960/2015).

Inclusive, quando a vida sofre suas transformações mais tumultuadas, como em tempos revolucionários, em meio à suposta mudança de todas as coisas, do antigo se conserva muito mais do que se poderia crer, integrando-se com o novo numa nova forma de validez. (Gadamer, 1960/2015, p. 373-374).

A essência da tradição caracteriza-se efetivamente pelo seu caráter de linguagem e adquire seu pleno significado hermenêutico na forma da escrita. É na tradição escrita que o transmitido se encontra simultaneamente presente para qualquer atualidade, em uma espécie de coexistência entre passado e presente. Compreender, nesse caso, "ganha uma possibilidade autêntica de avançar os limites e ampliar seu horizonte, enriquecendo assim seu próprio mundo com toda uma nova dimensão de profundidade” (Gadamer, 1960/2015, p. 505).

A tarefa hermenêutica frente aos textos escritos é reconverter o texto em linguagem, ou seja, através da relação do intérprete com o que é visado, possibilitar “o processo da compreensão que se move inteiramente na esfera de sentido mediada pela tradição da linguagem" (Gadamer, 1960/2015, p. 506), e não a mera decifração de sua literalidade. Ao desvincular-se da reconstrução de uma experiência passada, a compreensão hermenêutica propõe-se estabelecer a participação no que o texto comunica ao intérprete, assim permite, uma atualização sobre o que foi dito. Nesse sentido,

[...] o texto adquire uma existência autônoma, independente do escritor ou do autor, e do endereço concreto de um destinatário ou leitor. De certo modo, o que é fixado por escrito se eleva aos olhos de todos para uma esfera de sentido na qual pode participar todo aquele que esteja em condições de ler. (Gadamer, 1960/2015, p. 507).

Essa autonomia oportuniza que o intérprete seja levado a pensar sobre o pensado, livre de todo o caráter psicológico próprio do autor. Tal autonomia do sentido despoja-se de qualquer contingência inerente ao texto, o que confere o real valor à compreensão hermenêutica. É mais que uma opinião estranha: é uma pretensão de verdade, em virtude da desvinculação “do que é dito com relação a quem o disse e em virtude do caráter de duração conferido pela escrita” (Gadamer, 1960/2015, p. 510).

Assim, considerando que o horizonte é a perspectiva que delimita tudo o que pode ser abarcado a partir de um determinado ponto, o horizonte de sentido da compreensão hermenêutica não se restringe à perspectiva original do autor ou do destinatário a quem foi originalmente escrito o texto (Gadamer, 1960/2015).

Por isso, uma tarefa que nos é colocada constantemente é a de impedir uma assimilação precipitada do passado com as próprias expectativas de sentido. Só então poderemos ouvir a voz da tradição tal como ela pode fazerse ouvir em seu sentido próprio e diverso. (Gadamer, 1960/2015, p. 404, grifo nosso).

A propósito, segundo Gadamer (1960/2015), o sentido apreendido da tradição é o que se destaca em uma relação recíproca entre intérprete e texto. É o horizonte de um presente formado pelos preconceitos do intérprete que precisam ser permanentemente postos à prova pelo encontro entre o passado do texto e a compreensão da tradição que o intérprete procede, em um constante vir-a-ser. Assim, “compreender é sempre o processo de fusão desses 
horizontes presumivelmente dados por si mesmos" (p. 404). A fusão de horizontes, aludida aqui, ocorre constantemente sob a vigência da tradição, uma vez que a relação de tensão entre passado e presente, através do questionamento voltado ao que a tradição vem a ser para o intérprete, promove a atualização, ou seja, a projeção de um horizonte que se distinga do presente, que "implica a reconquista dos conceitos de um passado histórico de tal modo que esses contenham também nosso próprio conceber" (p. 488).

A importância do questionar representa, em uma perspectiva hermenêutica, pôr em suspenso o sentido próprio do texto e possibilitar a emergência da atualização. A pergunta permite acessar as possibilidades de sentido derivadas da relação do intérprete com o texto.Atualização, assim, referese ao fato de que o sentido de um texto sempre ultrapassa o sentido doado pelo seu autor, estando sempre propenso a uma nova releitura, de forma que a compreensão traz consigo um caráter produtivo, criativo e original, ao invés de meramente reprodutivo. Desta forma, compreender sempre será, necessariamente, atualizar, uma vez que sempre logra um novo entendimento, de modo único e diferente (Gadamer, 1960/2015).

Por isso, não pode haver uma interpretação correta 'em si', justamente porque em cada uma está em questão o próprio texto. A vida histórica da tradição consiste na sua dependência a apropriações e interpretações sempre novas. Uma interpretação correta 'em si' seria um ideal desprovido de pensamento, que desconhece a essência da tradição. Toda interpretação deve acomodar-se à situação hermenêutica a que pertence. (Gadamer, 1960/2015, p. 514).

E essa situação hermenêutica a que pertence a interpretação realiza-se na concreção do próprio sentido em seu momento de aplicação. Dessa forma, "compreender um texto significa sempre aplicá-lo a nós próprios" (Gadamer, 1960/2015, p. 515).

A nosso ver, metodologicamente pensando, a compreensão hermenêutica é uma construção processual que ocorre de modo intrínseco no próprio acontecer da tradição, cujas perguntas disparadoras desse processo de pesquisa se sustentam na atualização e mudança histórica que lhe são inerentes.

Se o próprio núcleo do problema hermenêutico é que a tradição como tal deve ser compreendida cada vez mais de modo diferente [por conta do seu caráter histórico-efeitual], então - a partir do ponto de vista lógico - o que está em questão é a relação entre o geral e o particular. Compreender passa a ser um caso especial da aplicação de algo geral a uma situação concreta e particular. (Gadamer, 1960/2015, p. 411).

Dessa forma, a conveniência do método hermenêutico-filosófico está no caráter prático, efetivo e ético dos seus conceitos. Seu critério de validade encontra-se na possibilidade de aplicação do conhecimento às situações concretas, cujo sentido é esboçado de modo conveniente e provisório, mas determinado pelo objeto estudado inserido no próprio acontecer da tradição.

Baseado na rede conceitual hermenêuticofilosófica (Gadamer, 1960/2015) exposta, desenvolveu-se o procedimento metodológico da pesquisa sobre a noção de abordagem centrada na pessoa (Bezerra, 2018) através de três fases distintas, inspiradas na proposta de Lima e Mioto (2007) voltada à pesquisa bibliográfica em geral, para obtenção de uma compreensão hermenêutica do problema proposto:

a) Investigação das informações, que envolveu dois momentos específicos e sucessivos: o levantamento do material bibliográfico e o levantamento das informações. No levantamento do material bibliográfico, classificou-se o material selecionado, a partir de leitura de reconhecimento e da leitura exploratória, como fonte de pesquisa. A leitura de reconhecimento do material bibliográfico caracterizou-se por ser rápida e voltada para identificação de obras relacionadas ao tema, em bibliotecas e bases de dados computadorizadas. Empreendeu-se uma leitura exploratória, de modo complementar, que consistiu em leitura rápida de sumários e manuseio de obras para comprovar se as referências selecionadas interessavam, de fato, ao estudo. Em seguida, através do levantamento das informações, fez-se o detalhamento da busca realizada inicialmente no levantamento bibliográfico para localizar as obras que seriam pesquisadas. Nesse momento, a leitura foi seletiva, ou seja, voltada para determinar o material que de fato possuía relação direta com os objetivos da pesquisa.

b) Análise compreensiva: nessa fase da pesquisa, uma vez localizado o material a ser pesquisado, buscou-se expor de modo ordenado os dados obtidos, através da leitura crítico-reflexiva, na forma de categorias conceituais. De acordo com o método aqui escolhido, tratou-se do delineamento do círculo hermenêutico no processo de aproximação inicial com os textos que foram analisados. Nesse sentido, considerou-se epistemologicamente a relação de significância mútua entre o todo desses textos e as partes que os compõem. Foi, também, nessa fase que emergiram os preconceitos do pesquisador, presentes originariamente em leituras e derivados da exposição inicial aos textos que foram analisados. Esse aspecto exigiu do próprio autor um exame desses preconceitos através do processo de revisão das leituras crítico-reflexivas realizadas, ou seja, dos estudos críticos dos textos analisados, que visaram 
ordenar e sumarizar as informações ali contidas.

c) Síntese hermenêutica: realizou-se o exercício reflexivo de uma hermenêutica sobre o objeto de estudo da pesquisa através de uma leitura interpretativa. Para isso, foi necessário o estabelecimento de uma atitude de abertura à opinião dos textos que foram analisados, ou seja, receptividade à alteridade envolvida nas leituras, sem desconsiderar o próprio horizonte de Bezerra (2018) enquanto intérprete, bem como a relação ambígua de familiaridade e estranheza entre texto e intérprete.

Tratou-se, nesse caso, de uma dinâmica análoga ao jogo e à conversação, nos quais o intérprete, sem se orientar por um roteiro fixo e pré-estabelecido se permite ao encontro de outros horizontes de compreensão (Gadamer, 1960/2015). A proposição de uma hermenêutica nessa fase considerou a possibilidade do desvelamento de um sentido possível, que pôde ser confirmado através da fusão de horizontes entre o movimento dos textos analisados e o movimento do autor na condição de intérprete, que necessariamente se complementou na capacidade de aplicação desse sentido sobre o próprio horizonte constituído no decorrer da produção textual da referida pesquisa.

\section{Considerações Finais}

Opresente artigo procurou apresentar o percurso teórico-metodológico desenvolvido pelo primeiro autor, e sob orientação do segundo, em pesquisa bibliográfica realizada em construção de Dissertação de Mestrado. Utilizou-se, como referência teórica, a hermenêutica filosófica de Gadamer, cuja adequação relaciona-se à especificidade do objeto de estudo em questão: a noção de abordagem centrada na pessoa. Para isso, foi necessário inicialmente identificar os aspectos singulares desse objeto em sua constituição original, uma vez que a terminologia em questão foi formulada apenas em 1975 por Carl Rogers e John Wood (2013), após décadas da teoria rogeriana acerca das relações humanas ser identificada pública e quase exclusivamente com a sua aplicação clínico-psicoterápica. Ao abdicar do sentido da abordagem centrada na pessoa como sendo uma ampliação das áreas de aplicação da terapia centrada no cliente, demonstrou-se que se trata de um novo horizonte conceitual que traz consigo uma série de vetos (Wood, 1994/2008), aqui chamados de vetos woodianos. Assim, ao tomar a noção de abordagem centrada na pessoa como um problema de pesquisa - o que é abordagem centrada na pessoa -, o passo seguinte foi apresentar o caminho a ser percorrido para o desenvolvimento dessa pesquisa.

A escolha da hermenêutica filosófica gadameriana foi utilizada por atender e respeitar os vetos woodianos, que são acolhidos nessa crítica ao paradigma metodológico científico moderno justamente na consideração da constituição do saber em seu contexto histórico-cultural e da implicação ao problema ético da concreção de uma teoria. Sustentada sobre uma base pré-estabelecida, anterior ao próprio saber a ser constituído entre o intérprete (sujeito) e o texto a ser interpretado (objeto de estudo), foi necessário articular a rede de ideias formada pelas concepções preconceito, linguagem, tradição, atualização e fusão de horizontes para, finalmente, apresentar o percurso metodológico desenvolvido e sustentado nesse horizonte conceitual.

As reflexões feitas sobre a noção de 'abordagem centrada na pessoa' nesse artigo foram limitadas ao necessário para o esclarecimento do objeto de estudo sobre o qual foi constituído, posteriormente, o percurso teórico-metodológico aqui apresentado. Ademais, tal demarcação serve de parâmetro para afirmar o potencial da proficuidade pouco explorada referente à aproximação e à articulação entre a abordagem rogeriana em Psicologia e a perspectiva filosófica gadameriana.

Nesse sentido, a trajetória de pesquisa realizada pelo primeiro autor (Bezerra, 2018), completamente inserida no horizonte conceitual da ACP, também corresponde à premissa gadameriana sobre a hermenêutica presente nesse caminhar: não se trata da aplicação de uma "doutrina da arte" do compreender, como um "sistema de regras artificiais capaz de descrever o procedimento metodológico das ciências do espírito" (Gadamer, 1960/2015, p. 14). Pelo contrário; propõe libertar-se da tarefa restritiva e ortopédica de um método que estabelece previamente um como fazer, considerando a possibilidade de dar corpo ao convite de Gadamer em se abrir ao que "nos acontece além do nosso querer e fazer" (Gadamer, 1960/2015, p. 14). Como no caso da pesquisa tomada como referência (Bezerra, 2018), compreender hermeneuticamente a noção de abordagem centrada na pessoa é buscar na finitude do próprio ato dessa compreensão aquilo que o percurso, que é processual e dialético, pode ir desvelando ao autor como verdade, ainda que tênue e profundamente experiencial.

Não há compromisso com o fechamento. Nesse caminho que apenas sinaliza possibilidades, vislumbra-se a potencialidade da interlocução conceitual entre a ACP e a hermenêutica filosófica gadameriana, considerando que um possível diálogo entre ambos (Gadamer e Rogers) ganha densidade no horizonte de uma relação de proximidade e diferença. A investigação hermenêutica sobre a identidade da abordagem centrada na pessoa permitiu a abertura de tais possibilidades, já que não há riscos à perda de sua identidade, mas apenas encontro e interlocução à margem do referencial empírico-cientificista equivocadamente associado aos pressupostos dessa abordagem.

Nesse acontecer do percurso teóricometodológico desenvolvido na Dissertação que serviu de base para esse artigo (Bezerra, 2018), 
foi possível o exercício desse re-conhecimento (enquanto novo conhecimento) produtivo, uma vez que houve abertura e estranhamento por parte do intérprete quando em extensas conversações com a tradição, representada nesse percurso, principalmente, pelos escritos de Carl Rogers e John Wood. O texto resultou desse diálogo em que Bezerra (2018) se reconhece mudado pelas ideias derivadas desse processo, mobilizado pela necessidade, para a potencial atualização da ACP, do estabelecimento, de modo cada vez mais consistente e contínuo de pontes de diálogo entre o presente e o passado, entre o antigo e o novo. Afinal, é nesse sentido que, do ponto de vista hermenêutico-filosófico, sobressai a relevância da tradição - enquanto transmissão - para a compreensão atualizada de uma questão, de um problema ou mesmo de um paradigma; daí por que a tarefa de compreender é sempre "pré-conceituosa", potente e criativa.

\section{Referências}

Abbagnano, N. (2003). Dicionário de Filosofia. São Paulo: Martins Fontes.

Bezerra, E. N. (2018). Uma compreensão hermenêutico-filosófica da noção de abordagem centrada na pessoa (Dissertação de Mestrado em Psicologia). Universidade Federal do Maranhão, São Luís.

Boainain Júnior, E. (1998). Tornar-se transpessoal: transcendência e espiritualidade na obra de Carl Rogers. São Paulo: Summus.

Branco, P. C. C. (2010). A noção de organismo no fieri teórico de Carl Rogers: uma investigação epistemológica (Dissertação de Mestrado em Psicologia). Universidade Federal do Ceará, Fortaleza.

Branco, P. C. C. (2015). Psicologia humanista de Carl Rogers: recepção e circulação no Brasil (Tese de Doutorado em Psicologia). Universidade Federal de Minas Gerais, Belo Horizonte.

Gadamer, H. G. (1998). O problema da consciência histórica.Rio de Janeiro: Fundação Getúlio Vargas. (Originalmente publicado em 1963)

Gadamer, H. G. (2015). Verdade e método: traços fundamentais de uma hermenêutica filosófica. Petrópolis: Vozes; Bragança Paulista: Editora Universitária São Francisco v. 1. (Originalmente publicado em 1960)

Gobbi, S. L., Missel, S. T., Justo, H. \& Holanda, A. (2005). Vocabulário e noções básicas da abordagem centrada na pessoa.São Paulo: Vetor.

Lawn, C. (2011). Compreender Gadamer. 3. ed. Petrópolis: Vozes.
Lima, T. C. S. \& Mioto, R. C. T. (2007). Procedimentos metodológicos na construção do conhecimento científico: a pesquisa bibliográfica. Revista Katálys , 10(esp), 169-178.

Martin, J. \& Dawda, D. (1999). Beyond Empathy: a hermeneutically inspired inquiry into interpessoal understanding in psychotherapy. Theory $\&$ Psychology, 9(4), 459-481.

Massimi, M., Campos, R. H. F.\& Brozek, J. (2008). Historiografia da Psicologia: métodos. In: Freitas, R. H. de (Org.). História da psicologia: pesquisa, formação, ensino. Rio de Janeiro: Centro Edelstein de Pesquisas Sociais. Disponível em http://books.scielo.org/id/c2248/pdf/freitas-9788599662830.pdf.

Melo, S. M. V. de. (2012). A saga de Hefesto: hermenêutica colaborativa como possibilidade de ação humanista-fenomenológica em clínica do trabalho. (Tese de Doutorado em Psicologia Clínica). Universidade Católica de Pernambuco, Recife.

Moreira, V. (2010). Revisitando as fases da abordagem centrada na pessoa. Estudos de Psicologia, Campinas, 27(4), 537-544

Rennie, D. L. (2007). Methodical Hermeneutics and Humanistic Psychology. Humanistic Psychologist, 35(1), 1-14.

Rogers, C. R. (1985). Toward a more human science of the person. Journal of Humanistic Psychology, 25 (4), 7-24.

Rogers,C. R. (1978). Sobre o poder pessoal. São Paulo: Martins Fontes (Originalmente publicado em 1977).

Wood, J. K. (2013). Sete verões entre pessoas: diário de bordo sobre a abordagem centrada na pessoa em grandes grupos. São Paulo: Via Lettera.

Wood, J. K., Doxsey, J. R., Assumpção, L. M., Tassinari, M.A., Japur, M., Serra, M. A. \& Cury, V. E. (2008). Abordagem centrada na pessoa. Vitória: EDUFES. (Originalmente publicado em 1994)

Worsley, R. (2016). Narratives and lively metaphors: hermeneutics as a way of listening. Person-Centered \& Experiential Psychotherapies, 11(4), 304-320.

Edson do Nascimento Bezerra, Universidade Federal do Maranhão. Email: en.bezerra@gmail.com

Almir Ferreira da Silva Junior, Universidade Federal do Maranhão 
1 No contexto aqui apresentado, usarei letras maiúsculas nas iniciais de Abordagem Centrada na Pessoa, também abreviado como ACP, sempre que me referir, de modo geral, à fase final da produção de Carl Rogers ou à identificação do seu legado teórico-prático principalmente na Psicologia; e usarei letras minúsculas nas iniciais de abordagem centrada na pessoa sempre que me referir à terminologia cunhada por Carl Rogers e John Wood em 1975, que foi objeto de análise na pesquisa aqui considerada.

2 Noção desenvolvida pelo filósofo Emmanuel Lévinas (1906-1995) sobre a condição do ser que não pode ser totalizado por qualquer conceituação. "Para ele, não se trata da questão do ser, mas de pôr o ser em questão e trazer para o debate filosófico o 'outramente que ser', o não poder-ser-de-outra-forma que não ser pelo e para o Outro" (Vieira \& Freire, 2006, p. 426)

3 Nome genérico, sem tradução exata para o português, que está associado a todo tipo de atividades relativas a grupo (encontra alguma correspondência e é invariavelmente traduzida por 'oficina'). É uma modalidade de grupo intensivo cujo objetivo está associado ao título do trabalho em questão (p.ex.: Creativity workshop ou 'oficina de criatividade'). Na Abordagem Centrada na Pessoa, Workshop é sinônimo de grupos de encontro"(Gobbi, Missel, Justo \& Holanda, 2005, p. 154 , grifos dos autores).

${ }^{4}$ Em latim, significa máscara (no sentido de personagem) e foi assim tratada pelo estoicismo popular no período helenístico da Grécia Antiga, para designar os papéis representados pelo homem no decorrer de sua vida (Abbagnano, 2003).

5 Saber que compõe as ciências do espírito ou ciências morais, cujo objeto é o humano e o que este sabe sobre si mesmo, cujo saber deve orientar o seu fazer (Gadamer, 1960/2015).

6 Trata-se da ciência, para os gregos, representada pelo paradigma da matemática, como um saber do inalterável, que repousa sobre a demonstração e que, por conseguinte, qualquer um pode aprender (Gadamer, 1960/2015).

7 Aqui compreendido no sentido hermenêutico da capacidade deste autor, enquanto sujeito, de reconstituição dos textos a partir da sua compreensão do que se diz nele (Gadamer, 1960/2015). 